\title{
RACKING RESISTANCE OF PREFABRICATED TIMBER-GLASS WALL ELEMENTS
}

\author{
Dr Miroslav Premrov* \\ Faculty of Civil Engineering, University of Maribor, Maribor, Slovenia \\ Boštjan Ber \\ Kager hiša DOO, Ptuj, Slovenia \\ Dr Andrej Štrukelj \\ Faculty of Civil Engineering, University of Maribor, Maribor, Slovenia
}

Importance of building large-size glazing into timber structures has significantly grown over the last decade. This was one of the major reasons for carrying out the presented experimental research on timber structures with a fixed glazing placed in the external sides or in the middle of the timberframe wall elements. Timber frame, to which glass pane is directly attached, forms the composite wall element, which contributes to stability of the entire system with its load capacity. Different types of adhesives with specific characteristics were used and they consequently caused different impacts on a wall composite. Both concepts, with bilateral glass as well as single glass lining in the middle of profile, are presented.

Key words: Timber, Glass, Resistance, Stability, Experiments, Monotonic tests

\section{INTRODUCTION}

Timber is a non-demanding material for prefabrication due to its organic structure and low density. It is also an ideal construction material from the viewpoint of energy efficiency since $\mathrm{CO} 2$ emissions in production of a timber element tend to be approximately two times lower that those present in manufacturing an equivalent brick element, three times lower than in the case of a concrete element and six times lower than $\mathrm{CO} 2$ emissions in steel element production. Nevertheless, timber achieved recognition as one of the oldest building materials in different countries worldwide. On the other hand, the grey energy consumption of glass is very high $(15.9 \mathrm{MJ} / \mathrm{kg})$, greater even as by brick or concrete, thus the energy aspect of glass was often treated as a weak point in the past. However, in the last few decades glass has become one of the main drivers of technical development for the purposes of the building industry. Owing to significantly improved its optical and especially energy related, i.e insulating properties, glass has become an ever more widely used material and is no longer solely responsible for daylighting or the transparency of the building only. Another important novelty arising from the phenomenon of increasing the size of glazing surfaces in modern buildings is taking the load bearing function of glass into account, where its integration with other building materials plays a vital role. Dynamic evolution of the glazing in the last 40 years resulted in insulating glass products with highly improved physical and strength properties, suitable for application in contemporary energy-efficient buildings, not only as material responsible for solar gains and daylighting, but also as a component of structural resisting elements.

With suitable technological development and appropriate use, timber and glass are nowadays becoming essential construction materials as far as the energy efficiency is concerned. Integration of large and properly oriented glazed areas into timber structures represents a great potential for the construction of environment-friendly and energy-efficient buildings. With respect to the energy related facts, a major part of the glazing needs to be installed in the south-oriented façade for the purpose of better energy performance of a building, which leads to specific technical challenges in the field of structural behaviour of the load bearing wall elements with an enlarged glazing size, Žegarac and Premrov [01]. Even though energy-efficient, such construction systems can be extremely problematic when the building is 
exposed to horizontal loads. As a consequence, resisting problems can occur in timber-glass load-bearing wall elements exposed to havy horizontal actions like earthquake or wind.

\section{GLASS IN PREFABRICATED TIMBER-FRAME WALLS}

Timber is commonly associated with lightweight construction although it is ubiquitous as a building material. Recently, there are many arguments for timber-frame residential buildings such as built-in materials show environmental excellence, lower energy consumption while preparing built-in materials and as one of the most important the speed of construction. Due to high degree of prefabricated elements timber-frame buildings are built in essential shorter period of

a)

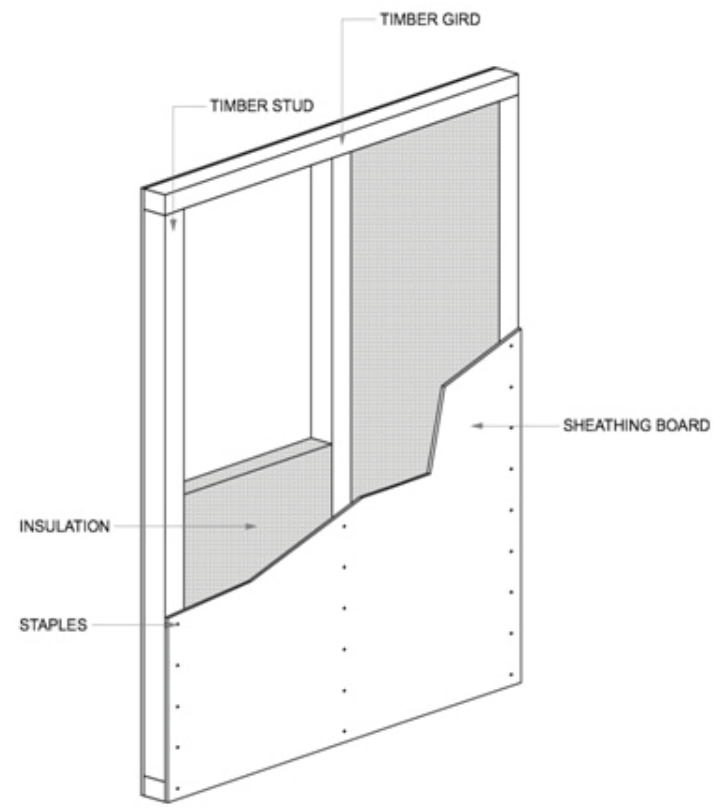

time when compared to conventional brick building techniques. It also means that during construction the building is exposed to inconvenient weather conditions only shortly.

There are four main construction systems of timber-frame residential buildings: a.) classical post and beam system, b.) classical balloonframe system, c.) cell system, d.) prefabricated timber-frame panel system. In our study we will be dedicated to the prefabricated timber-frame panel system, originates from the ScandinavianAmerican construction methods, i.e. balloonframe and platform-frame construction types whose assembly-works take place on-site. We can distinguish between an old single-panel wall system (Figure 1a) and in this time widely used macro-panel wall system (Figure $1 b$ ).

b)

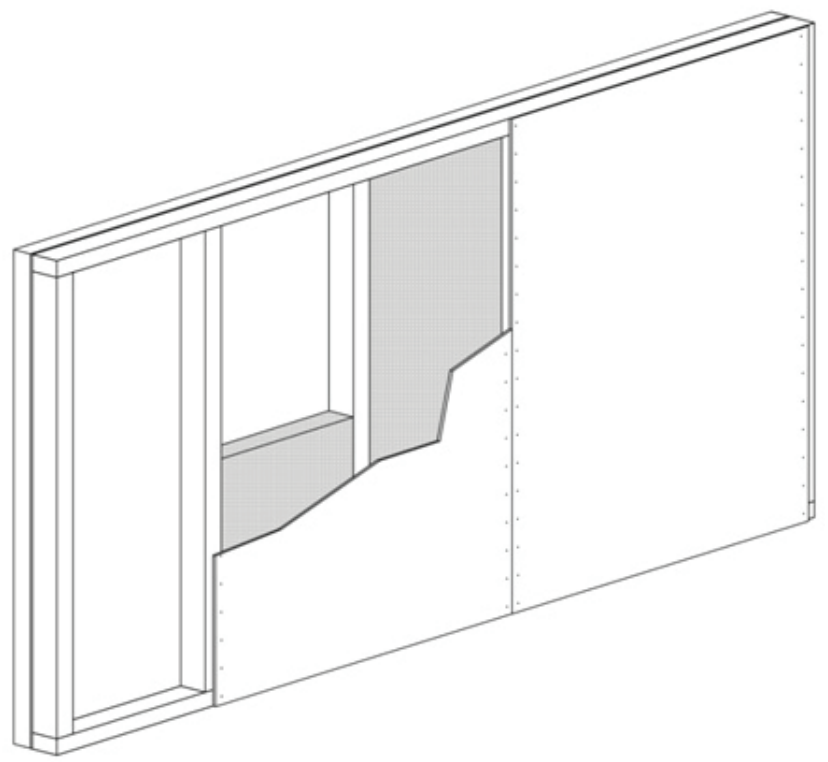

Figure 1: Prefabricated timber-frame systems; a.) single-panel, b.) macro-panel.

In the both structural systems the timber-frame walls as main vertical bearing capacity elements of usually typical dimensions with a width of $b=$ $1250 \mathrm{~mm}$ (single-panel) or $\mathrm{b}=\mathrm{n} \cdot 1250 \mathrm{~mm}$ (macro-panel) and a height of $h=2500-2600 \mathrm{~mm}$ are composed of a timber frame and of sheets of board-material fixed to the both sides of the timber frame. In the macro-panel structural system the wall elements with a total length of up to 12.5 metres are now entirely produced in a factory.

There are many types of panel sheet products available which may have some structural capacity such as wood-based materials or fibre- plaster boards (FPB). Between the timber studs a thermo-insulation material is inserted which thickness depends on the type of the wall in a sense to improve the thermal properties of the external walls. The influence of different types of the sheathing boards is already deeply analysed and discussed in Premrov and Kuhta [02].

However, the main contribution of the presented research is in replacing the classical sheats with the glass panes, as it is schematically presented in Figure 2. One of the main drawbacks of glass used as a load bearing material lies in its being a relatively brittle material with mostly a significantly low degree of post-cracking resistance. 
On the other hand, glass has a high modulus of elasticity of approximately $70 \mathrm{GPa}$, which is a value about 6 -times higher than that of softwood in the grain direction, although 3-times lower than that of steel and equal to that of aluminium. Thus we can claim that glass is relatively stiff mate- rial and that properly inserted glass elements can significantly contribute to the stiffness of the structure. A difficulty still remaining is seen in the behaviour of glass, which is almost linear-elastic until failure.

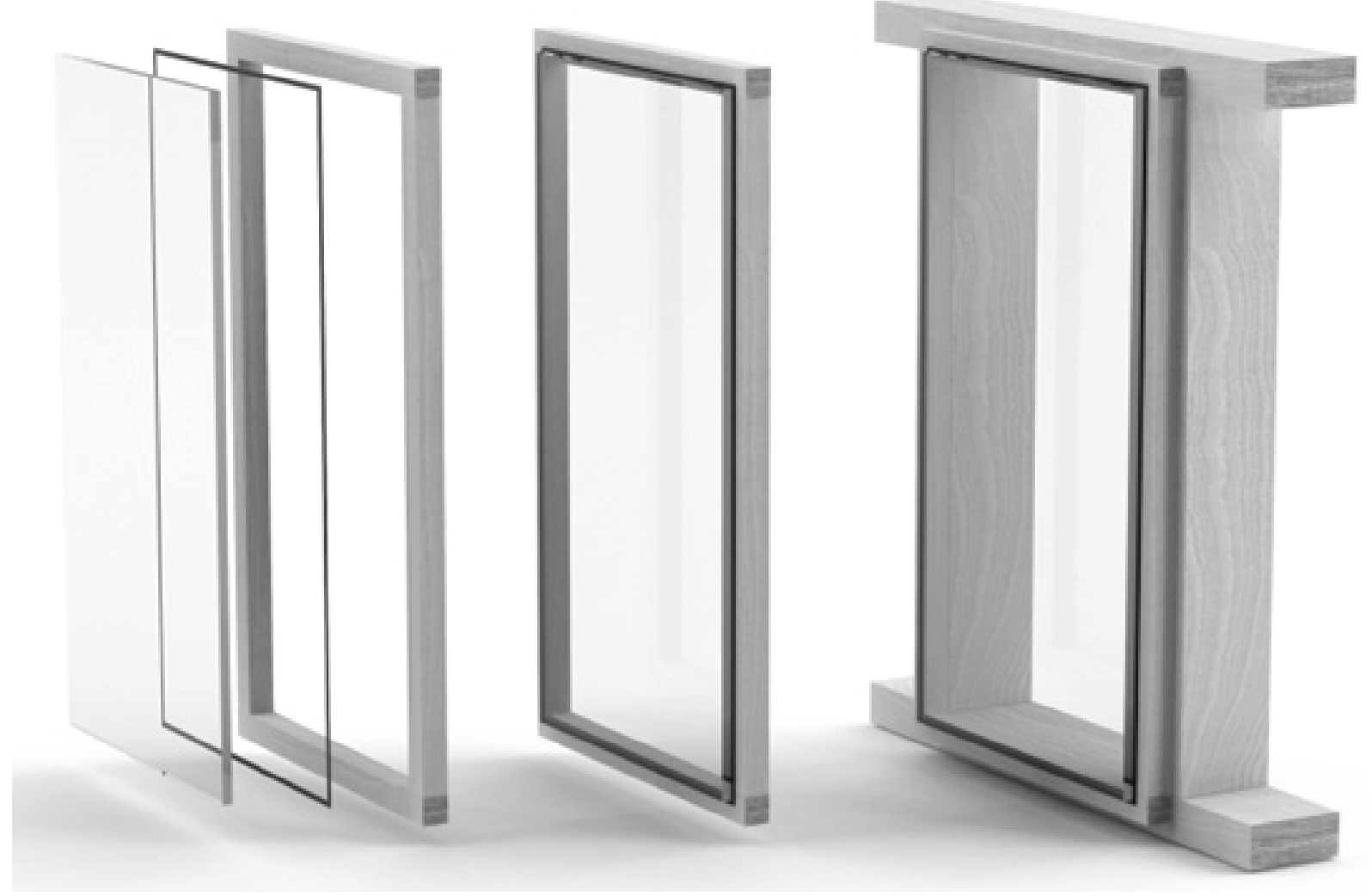

Figure 2: Timber-glass prefabricated walls - replacing classical sheathing boards with glass panes

It is consequently of utmost importance for adhesives to assure resistance and a high range of ductility of such composed load bearing elements with quite different material properties, simultaneously to finding balance between strength and deformability. Adhesives must also allow for expansion and shrinkage of timber, according to loading and humidity variations, Cruz and Pequeno [03]. According to Cruz adhesives used in timber-glass composites can be classified into three main groups: a.) Highly resistant and insufficiently flexible adhesives - rigid adhesives (acrylate, epoxy); b.) Highly flexible adhesives, yet insufficiently resistant to loading - elastic adhesives (silicone); c.) Adhesives that balance both key factors - strength and flexibility - semi-rigid adhesives (polyurethane, superflex polymers).

\section{EXPERIMENTAL STUDY}

We conducted research on the lateral load-bearing capacity of the timber-glass wall element with a two-sided glass sheathing glued to the outer side of the timber frame (Concept 1 in Figure $3 b$ ) and a single glass pane placed in the center of the cross section (Concept 2 in Figure 3b). A number of studies on combining glass with timber and those on the in-plane load-bearing capacity of glass panes have been so far carried out the Technical University of Vienna in Hochhauser et al. [4], which will be of assistance in the comparison with our experimental results. In their proposal the glazing placed on the external side of the timber frame was not directly glued to the timber frame but bonded with adhesives to the special substructure (Figure 3a) which is fixed with bolts to the external side of the timber frame. The most important technological advantage of such type of connection is a relatively simple replacement of the glazing replacement in the case of its breakage. 
a)

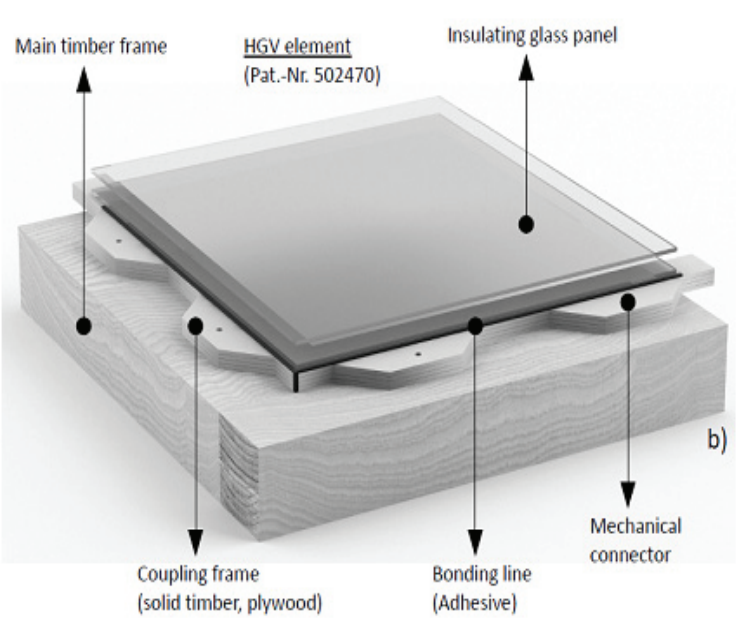

b)

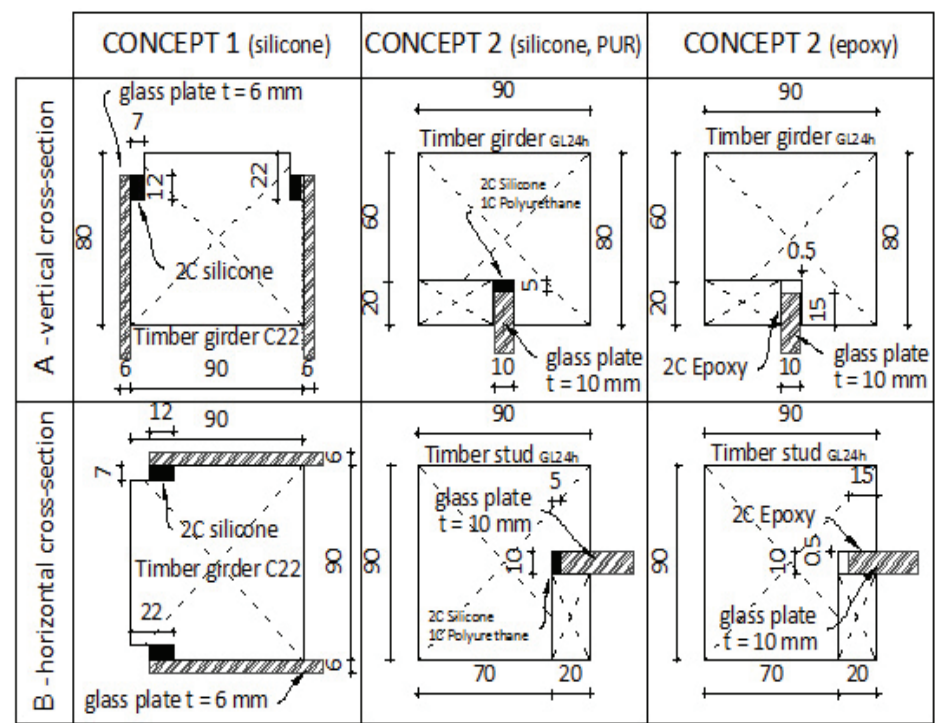

Figure 3: a) HGV concept, b) Slovenian concepts of connecting the glass pane to the timber frame (direct connection)

The test specimens consisted of a timber frame with the outside edges measuring 1250/2640 mm (Figure 4a), which used to be a standard size of wall panels tested in previous studies where a different sheathing material was used, ref. [03] to [06]. Vertical studs were composed of rectan- gular $90 / 90 \mathrm{~mm}$ timber elements with the size of horizontal girders being $90 / 80 \mathrm{~mm}$. During the testing process the panels were rotated by $90^{\circ}$ and fixed with the left vertical stud via three coil bars $\Phi 16$ into the stirrup consisting of two steel plates, as shown in Figure 4b.
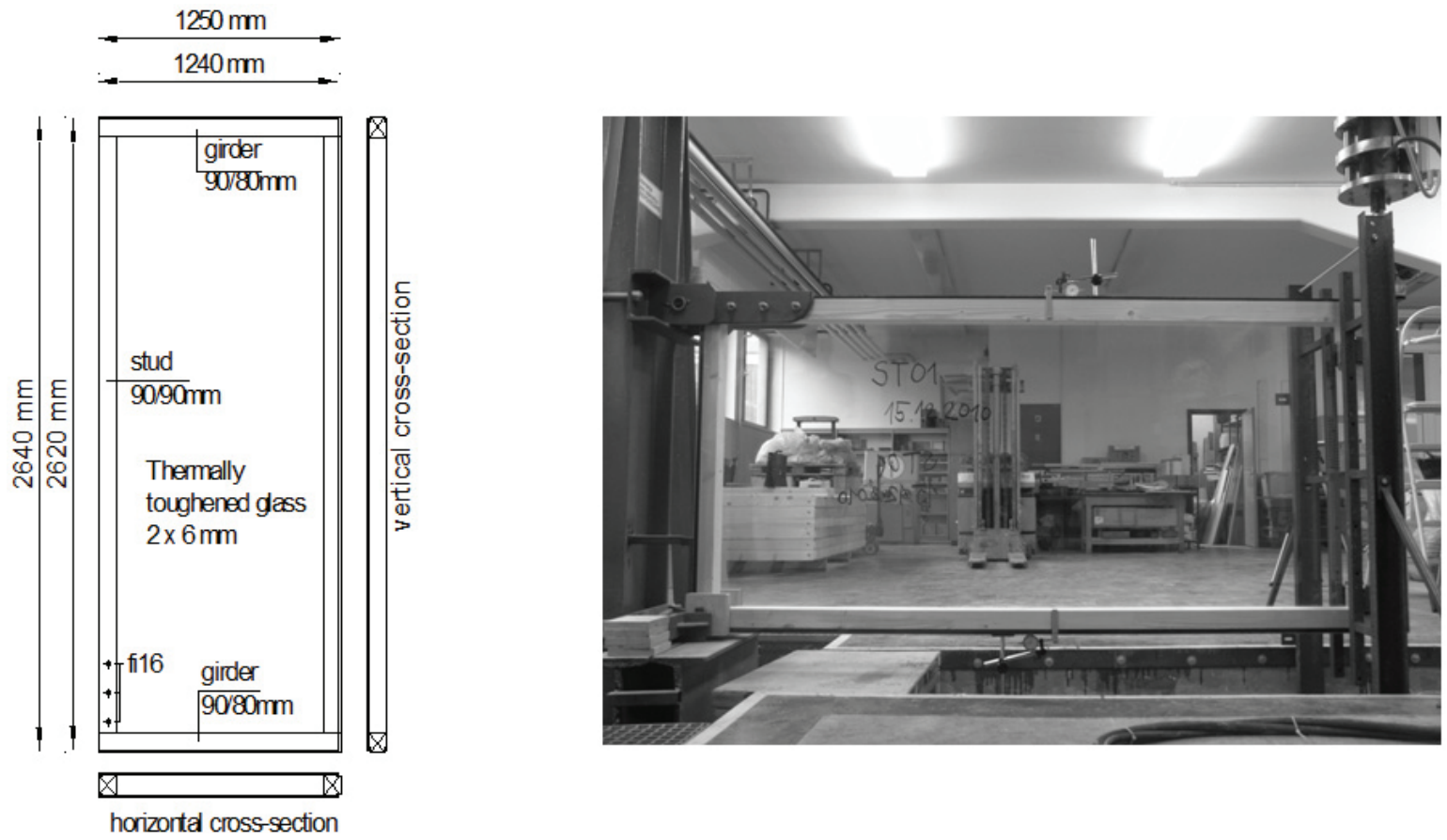

Figure 4: a) Cross-section of the test samples; b) Position of the test sample during the loading procedure 
Timber frame elements in both concepts were made of wood with a strength grade $\mathrm{C} 22$, glass panes consisted of toughened ESG glass and the adhesive used in the timber-glass joint was a two-component silicone adhesive type Ködiglaze $S$ (Concept 1), produced by Kömmerling [5]. In the second case (Concept 2), polyurethane (Kömmerling [06]) and epoxy adhesives (Kömmerling [07]) were additionally used, silicone was the same. Material properties of timber with a strength grade $\mathrm{C} 22$ were taken from EN 338:2003, with properties of thermally toughened glass being taken from EN 572-1:2004 and EN 12150-1:2000.

The results of all specimen groups are given in Figure 5 which shows the normalized values of vertical displacements $(w)$ relative to force $F$, sep- arately for each specimen. In specimens groups ST- O and ST-E, we witnessed an explosive collapse of a glass pane. In specimens groups ST$S$ and ST-P a failure occurred due to collapse of the upper left corner of the timber frame. Results of ST testing group were compared with testing groups of wall panels with different sheathing material by Premrov and Kuhta [08]. The timberglass wall elements were labelled as ST, while the labels of other test specimens mean the following: G2 - single FPB sheathing with a span of $\mathrm{s}=75 \mathrm{~mm}$ between the staples $(\mathrm{n}=4), \mathrm{G} 2 \mathrm{D}$ - double FPB sheathing with a span of $s=75$ $\mathrm{mm}$ between the staples ( $\mathrm{n}=1), \mathrm{G} 2 \mathrm{O}$ - single OSB sheathing with a span of $\mathrm{s}=75 \mathrm{~mm}$ between the staples $(n=3)$.

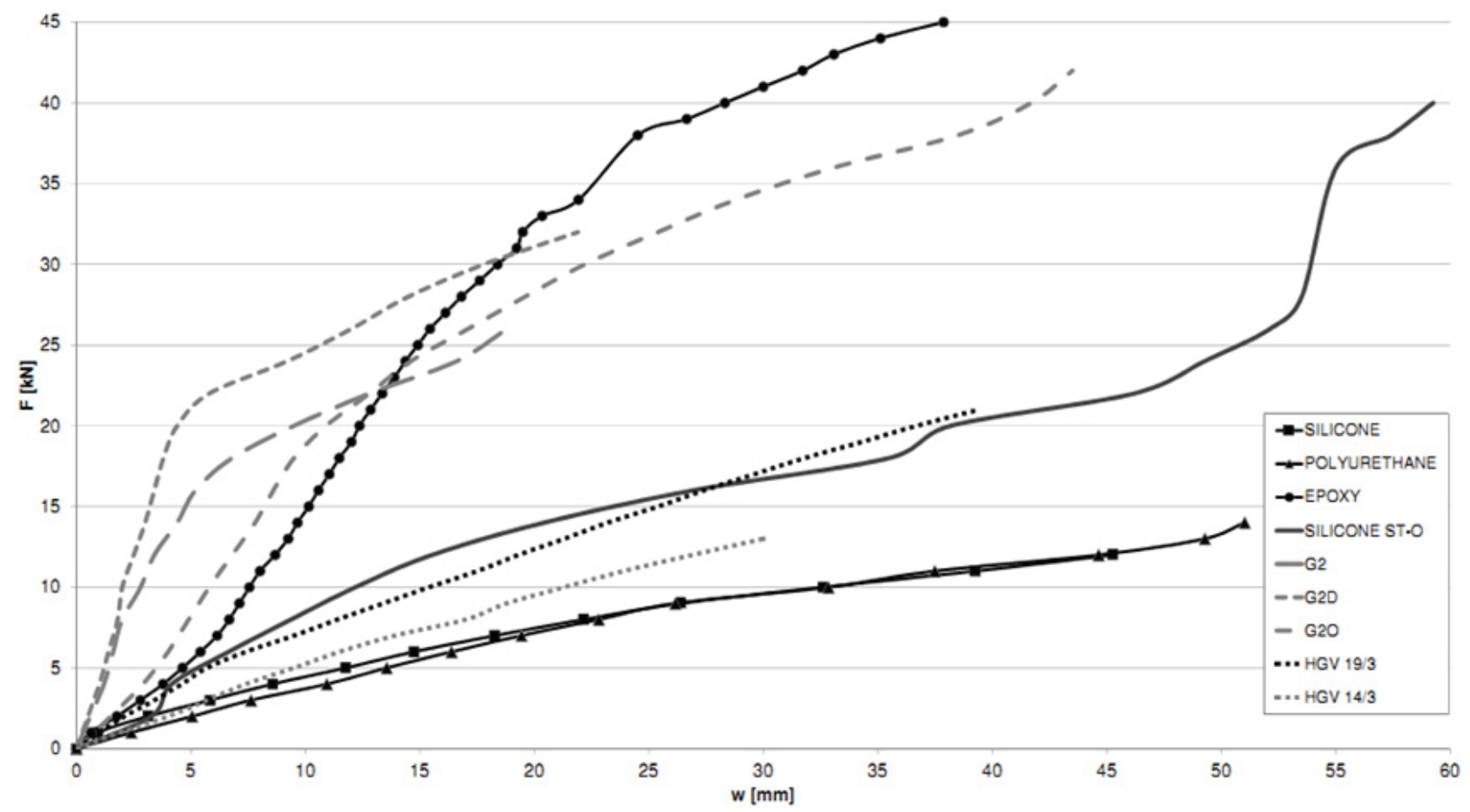

Figure 5: F-w diagrams of the test specimens with different types of the sheathing materials

Load-carrying capacity and stiffness of group ST-E can be compared with G2O. Almost identical stiffness and strength can be seen in groups ST-S and ST-P. Furthermore, it is clear that the specimens G2, G2D and G2O behave almost linear-elastic until the appearance of the first cracks. The continuation of the test caused reducing of stiffness $G 2$ and G2D due to increased slips in the connection planes as a result of fasteners plastification.

\section{CONCLUSION}

The results of the experimental researches were positive surprise since we did not expect such high values of failure forces, which are comparable to those of experimental researches including the usual sheathing materials (FPB, OSB). Nevertheless, the racking stiffness of timber-glass wall panels and softer adhesives (ST-O, SP-S, SP-P) was significantly lower (with the exception of the ST-E), as in the conventional sheathing material. In practice this would mean difficulty in achieving serviceability limit state. The reason 
for this phenomenon is too flexible contact between the glass pane and timber frame. Taking into account the significantly different mechanical properties of these materials, especially at high temperature load, we conclude that flexible joints should be used.

\section{ACKNOWLEDGEMENTS}

The support of the companies Kager hiša, Reflex and Sika Slovenia who donated the materials needed for the experiments is gratefully acknowledged. The research work is part of the project LBTGC selected on the international WoodWisdom-Net and fundad by the MIZŠ.

\section{LITERATURE}

1) Cruz P., Pequeno J., "Timber-Glass Composite Structural Panels: Experimental Studies \& Architectural Applications", Conference on Architectural and Structural Applications of Glass, Delft University of Technology, Faculty of Architecture, Delft, Netherlands, 2007.

2) Hochhauser W., Winter W., Kreher K., "HolzGlas-Verbundkonstruktionen - State of the Art, Forschungsbericht, Studentische Arbeiten", Technische Universitat Wien, Institut fur Architekturwissenschaften Tragwerksplanung und Ingenieurholzbau, 2011.
3) Kömmerling, "Product Information Ködiglaze $P$ - Special adhesive for bonding insulating glass units into the window sash", 2008.

4) Kömmerling, "Product Information Ködiglaze $S$ - Special adhesive for structural and direct glazing", 2008.

5) Kömmerling, "Product Information Körapox 558 - Two component reaction adhesive for bonding of metals, for example steel or aluminium to each other", 2011.

6) Premrov M., Kuhta M., "Experimental Analysis on Behaviour of Timber-Framed Walls with Different Types of Sheathing Boards".,Construction Materials and Engineering, Nova Science Publishers, 2010.

7) Premrov M., Kuhta M., "Influence of fasteners disposition on behavior of timber-framed walls with single fibre-plaster sheathing boards", Construction and Building Materials, 2009, vol. 2, iss. 7, pp. 2688-2693.

8) Žegarac Leskovar V., Premrov M., "An approach in architectural design of energy-efficient timber buildings with a focus on the optimal glazing size in the south-oriented façade", Energy and Buildings, 2011, vol. 43, iss. 12 , pp. 3410-3418.

Paper sent to revision: 07.02.2014.

Paper ready for publication: 15.03.2014. 